\title{
MOTIVASI BELAJAR MAHASISWA SARJANA KEPERAWATAN STIKES BINA USADA BALI
}

\author{
A.A. Kompiang Ngurah Darmawan*, Bagus Ranu Prayogo \\ STIKES Bina Usada Bali \\ e-mail: agungdarmawan32@yahoo.com*
}

\begin{abstract}
Students as Agent of Change must be motivated when motivation is low, generally it is assumed that the achievement in question will be low and it is likely that he will not achieve the learning goals. Based on preliminary studies conducted at STIKES Bina Usada Bali data obtained from third semester students as many as 102 students with a percentage of $60 \%$ of the number of third semester students following improved grades and substandard. The general objective of this study was to determine the level of learning motivation of undergraduate nursing students in the third semester at STIKES Bina Usada Bali.The research design used in this study is qualitative research. The sampling technique used in this study was purposive sampling using 5 subjects. Data collection techniques used are interviews, observation and documentation studies.The results of the study indicate that the reasons for students choosing to study at STIKES Bina Usada Bali are two, namely the facilities and Study Programs offered are adequate. There are two processes for students to choose lectures, namely PMDK and Public pathways. While the learning motivation of Nursing S1 undergraduate students in the third semester is still low, this is evidenced by the existence of general factors such as forced parents, learning H-1 before UAS, studying when the UAS is implemented, assuming values are still above the standard and motivated when the values are below standard.
\end{abstract}

Keywords: choosing a lecture, college entrance process, learning motivation

\begin{abstract}
ABSTRAK
Mahasiswa sebagai Agent of Change harus punya motivasi apabila motivasi rendah, umumnya diasumsikan bahwa prestasi yang bersangkutan akan rendah dan besar kemungkinan ia tidak akan mencapai tujuan belajar. Berdasarkan studi pendahuluan yang dilakukan di STIKES STIKES Bina Usada Bali diperoleh data mahasiswa semester III sebanyak 102 mahasiswa dengan presentase $60 \%$ dari jumlah mahasiswa semester III mengikuti perbaikan nilai dan substandard. Tujuan umum dari penelitian ini adalah untuk mengetahui Tingkat Motivasi Belajar mahasiswa S1 Keperawatan Semester III di STIKES Bina Usada Bali.Desain penelitian yang digunakan dalam penelitian ini adalah penelitian kualitatif. Teknik sampling yang digunakan dalam penelitian ini adalah purposive sampling dengan menggunakan 5 subjek. Teknik pengumpulan data yang digunakan yaitu dengan wawancara, observasi dan studi dokumentasi. Hasil penelitian menunjukkan bahwa alasan mahasiswa memilih kuliah di STIKES Bina Usada Bali ada dua yaitu fasilitas dan Program Studi yang ditawarkan memadai. Proses mahasiswa memilih kuliah ada dua yaitu jalur PMDK dan jalur Umum. Sedangkan motivasi belajar mahasiswa S1 Keperawatan semester III masih rendah hal ini dibuktikan dengan adanya faktor umum seperti paksaan orang tua, belajar H-1 sebelum UAS, belajar saat UAS dilaksanakan, menganggap nilai masih di atas standard dan termotivasi ketika nilai di bawah standar.
\end{abstract}

Kata kunci: memilih kuliah, proses masuk kuliah, motivasi belajar

\section{PENDAHULUAN}

Pendidikan dan pengajaran adalah suatu proses yang sadar tujuan. Tujuan dapat diartikan sebagai suatu usaha untuk memberikan rumusan hasil yang diharapkan mahasiswa setelah melaksanakan pengalaman belajar tercapai tidaknya tujuan pengajaran salah satunya adalah terlihat dari prestasi belajar yang diraih mahasiswa. Dengan prestasi yang tinggi, para mahasiswa mempunyai indikasi berpengetahuan yang baik.Salah satu faktor yang mempengaruhi prestasi mahasiswa adalah motivasi. Dengan adanya motivasi, mahasiswa akan belajar lebih keras, ulet, tekun dan memiliki konsentrasi penuh dalam proses belajar pembelajaran. Dorongan motivasi dalam belajar merupakan salah satu hal yang perlu dibangkitkan dalam upaya pembelajaran di sekolah (Hamdu \& Agustina, 2011).

Mahasiswa adalah orang yang mempunyai kedudukan yang istimewa dalam masyarakat terutama perannya sebagai Agent of Change (agen perubahan).Agent of Change identik dengan kekritisan berpikir dan melakukan suatu tindakan Sebagai Agent of Changemahasiswa harus punya motivasi sebagai faktor yang berpengaruh dalam mewujudkan keberhasilannya. 
Motivasi yang kuat akan menumbuhkan gairah, semangat dan perasaan senang untuk belajar. Sederhananya apabila mahasiswa tidak memiliki motivasi belajar maka tidak akan terjadi kegiatan belajar pada diri mahaiswa tersebut. Apabila motivasi rendah, umumnya diasumsikan bahwa prestasi yang bersangkutan akan rendah dan besar kemungkinan ia tidak akan mencapai tujuan belajar (Kiswoyati, 2011).

Berdasarkan studi pendahuluan yang dilakukan pada tanggal 24 November 2018 di STIKES Wira Medika Bali diperoleh data mahasiswa semester III berjumlah 123 mahasiswa dengan presentase $30 \%$ mahasiswa yang mengikuti perbaikan nilai dan substandard. Sementara studi pendahuluan yang dilakukan di STIKES Bina Usada Bali diperoleh data mahasiswa semester III sebanyak 102 mahasiswa dengan presentase $60 \%$ dari jumlah mahasiswa semester III mengikuti perbaikan nilai dan substandard.

Pentingnya motivasi belajar mahasiswa terbentuk antara lain agar terjadi perubahan belajar kearah yang lebih positif. Berdasarkan hal tersebut penulis tertarik untuk meneliti "Motivasi Belajar Mahasiswa Sarjana Keperawatan STIKES Bina Usada Bali ( Studi Pada Mahasiswa Semester III angkatan XIII)".

\section{METODE}

Rancangan penelitian yang digunakan dalam penelitian ini adalah rancangan penelitian kulitatif dengan interpretasi Hal yang akan dikaji adalah deskripsi mengenai bagaimana pengalaman orang lain dan apa maknanya bagi mereka. (Saryono \& Anggraeni, 2011).

Teknik pengumpulan data yang digunakan untuk penelitian kualitatif adalah wawancara mendalam, suatu kegiatan yang dilakukan untuk mendapatkan informasi secara langsung dengan mengajukan pertanyaan kepada narasumber (informan atau informan kunci) untuk mendapat informasi yang mendalam, kemudian yang kedua observasi mempunyai makna lebih dari sekedar teknik pengumpulan data. Namun dalam konteks ini observasi sebagai upaya peneliti mengumpulkan data dan informasi dari sumber data primer dengan mengoptimalkan pengamatan peneliti dan yang ketiga adalah observasi yaitu teknik pengumpulan data melalui studi dokumentasi diartikan sebagai upaya untuk memperoleh data dan informasi berupa catatan terulis/gambar yang tersimpan berkaitan dengan masalah yang diteliti.

Teknik analisis data yang digunakan dalam penelitian kualitatif adalah dengan mengacu pada konsep Milles \& Huberman yaitu interactive model (model interaktif) yang mengklasifikasikan analisis data dalam tiga langkah yaitu reduksi data (data reduction) merupakan proses pemilahan dan transformasi data kasar yang muncul dari catatancatatan tertulis di lapangan, Penyajian data (display data) sebagai sekumpulan informasi tersusun, Penarikan kesimpulan (verivikasi) yang dilakukan peneliti dalam penelitian ini dilakukan dengan membandingkan hasil penelitian dengan literatur kajian teori yang ada.

\section{HASIL}

Penelitian ini dilakukan di STIKES Bina Usada Bali yang beralamat di Jalan Raya Padang Luwih, Tegal Jaya, Dalung, Kuta Utara.

Penelitian ini terhenti pada 5 informan yang mampu memberikan kelengkapan data yang sesuai satu sama lainnya, sehingga mendapat kesimpulan yang valid untuk penelitian ini. Penelitian ini dilakukan dengan pengumpulan data melalui wawancara, studi dokumentasi dan observasi partisipan. Adapun penjelasan mengenai informan dalam penelitian berikut adalah nama dan semester sebagai berikut:

\section{Informan 1}

Informan 1 adalah An. Y Semester III. Mahasiswa ini termasuk individu yang sedikit tertutup dan sedikit bicara pada saat di wawancara.

\section{Informan 2}

Informan 2 adalah An. G Semester III, Mahasiswa ini termasuk individu yang acuh dan transparan.

Informan 3

Informan An. A. Mahasiswa semester III. Mahasiswa ini termasuk individu yang tanggap, terbuka dan komunikatif.

Informan 4

Informan An. D Mahasiswa semester III. Mahasiswa ini termasuk individu yang pendiam, cukup komunikatif dan terbuka.

\section{Informan 5}

Informan Tn. N Wali Kelas Program Studi S1 Keperawatan STIKES Bina Usada Bali ini termasuk individu yang ramah, terbuka dan tegas.

Adapun hasil wawancara mendalam di lapangan yang dilakukan pada tanggal 29 Mei 2019 adalah :

\section{Alasan-alasan memilih STIKES Bina Usada Bali}

Informan An. Y: 
"Satu rumah saya dekat, fasilitas gedung bagus dan terdapat lift, memiliki 4 lantai, serta dosen-dosen yang ramah, itu saja kak"

Informan II An. G:

"Karena saya lihat di brosur kak, fasilitas lengkap ada lift tidak perlu memakai tangga, terus ada AC, jadi saya tertarik untuk kuliah di STIKES Bina Usada Bali."

Informan III An. A:

"Karena dulu saya sudah mencoba daftar-daftar di kampus lain tetapi tidak ada jurusan S1 melainkan hanya terdapat jurusan D3 sehingga saya memilih di STIKES Bina Usada Bali."

Informan IV An. D :

"Awalnya itu saya diberi tahu kemudian saya datang ke sekolahnya lalu saya melihat gedung dari luar. Saat itu saya sudah tertarik dari awal sepertinya sekolahnya itu bersih dan fasilitasnya bagus, sehingga saya langsung memberitahu orang tua saya untuk sekolah di STIKES Bina Usada Bali."

\section{Proses Masuk di STIKES Bina Usada Bali}

Informan I An. Y:

"Saya di data dari sekolah kak, terus dinilai apakah sudah memenuhi persyaratan untuk mengikuti jalur PMDK, setelah itu baru daftar melalui jalur PMDK kak, yang menggunakan nilai rapot SMA sebagai salah satu syarat utamanya."

Informan II An. G:

"Saya mendaftar menggunakan jalur umum kak, saya waktuni tes tulis, tes fisik kesehatan,"

Informan III An. A:

"Jalur umum. Saya di tes tulis, tes kesehatan. Masuknya juga gak dipersulit malah dimudahkan"

Informan IV An. D:

"jalur umum, lewat-lewat tes. Tes tulis, tes warna, tes fisik, tes itu juga kan tes urin. Pas masuk juga gak ada kendala, malah kita dimudahkan untuk masuk kesini."

\section{Alasan Memilih Jurusan Keperawatan}

Informan I An. Y:

"Dipaksa sama orang tuanya kak, sebelumnya saya ingin kuliah di UNHI kak."

Informan II An. G:

"Kalau jujur dari orang tua kak. Saya dulu mau kuliah di STIKOM, jurusan komputer."

Informan III An. A:

"ee dari orang tua maunya di kesehatan. Saya sih sebenernya maunya ngambil di Universitas lain ya Cuma karna orang tua maunya di sini yaudah. Saya maunya ambil di Psikolog, Cuma karna disebelah udah penuh yaudah jadinya ambil kesehatan aja."

Informan IV An. D:

"Sebenarnya ini dari orang tua saya kak. Jadi dari kecil saya memang sudah disuruh ketika saya dewasa nanti kamu jadi perawat jadi karena dari orang tua saja. Kalau keinginan saya sebenarnya saya ingin menjadi presenter kuliah di jurusan bahasa."

\section{Cara-cara Mempersiapkan Diri Saat UAS}

Informan I An. Y:

"Kalau saat UAS saja saya belajar kak, pada pagi hari saja kak, santai saja kak."

Informan II An. G:

"saya tidak pernah belajar kak. Kalau UAS saya hanya berdoa saja kak."

Informan III An. A:

"Kalau UAS biasanya saya belajar sehari sebelum UAS kalau UTS saya tidak belajar."

Informan IV An.

"kalau saya, besok UAS hari ini saya belajar. Tidak pernah saya seminggu sebelum UAS karna saya pikir masih ada hari besok."

\section{Tanggapan Mahasiswa Saat Nilai UAS Rendah.}

Informan I An. Y:

"Biarkan saja kak."

Informan II An. G:

"Termotivasi kak, agar nanti tidak terlalu jauh nilainya dengan teman-teman kak, saya tetap menjalankan tetapi belajar jarang."

Informan III An. A:

"Biarkan saja. Kalau misalnya IPK nya masihbisa diselamatkan sepertinya tidak, kalau IPK tidak begitu rendah saya biarkan saja tetapi kalau sudah rendah sekali baru saya perbaiki."

Informan IV An. D:

"Kalau saat UAS kecil saya merasa sedih, pasti termotivasi, karena IPK nya kecil dan pasti diperbaiki. Karena kalau IPK kecil, kita pasti akan terhambat untuk mengurus ujian proposal dan skirpsi."

\section{Kendala Mengajar di STIKES Bina Usada Bali}

\section{Informan V Tn. A}

"Secara umum kendala mengajar tidak ada, hanya saja karakteristik setiap mahasiswa berbeda-beda tidak bisa disamakan, beberapa mahasiswa yang memang mudah mengerti ada yang sedikit sulit memahami materi, ada juga beberapa mahasiswa yang memang serius menerima materi ada juga yang masih suka 
bercanda. Hanya itu saja kendala kalau mengajar, tapi kita harus tetap sabar karena memang sudah menjadi kewajiban kita untuk membimbing mereka."

\section{Motivasi Belajar Mahasiswa STIKES Bina Usada Bali}

Informan V Tn. A

"Kalau menurut saya motivasi belajar mereka ada yang termotivasi ada yang tidak termotivasi, itu biasanya dikarenakan oleh banyak faktor seperti pergaulan teman sebaya maupun tuntutan dari keluarga. Tapi saya yakin mereka sebenarnya punya motivasi untuk belajar hanya saja mereka belum begitu memahami apa tujuan mereka belajar sebenarnya."

\section{PEMBAHASAN}

Berdasarkan hasil wawancara dengan narasumber atau informan, peneliti dapat meganalisis motivasi belajar mahasiswa S1 Keperawatan semester III STIKES Bina Usada Bali berdasarkan rumusan masalah diteliti:

\section{Alasan Mahasiswa Memilih Kuliah di STIKES Bina Usada Bali.}

Teori fenomenologi merupakan suatu usaha untuk mengungkap dan memahami suatu fenomena serta yang ada di balik suatu perkataan atau tingkah laku. Dengan demikian, dalam mempelajari dan memahaminya haruslah berdasarkan sudut pandang (paradigma) dan keyakinan dari individu tersebut yang mengalami langsung. (Almnshur, 2016). Namun pada penelitian ini lebih menggunakan sudut pandang yang pertama sesuai dengan yang dikatakan partisipan dalam mengungkapkan alasan memilih STIKES Bina Usada Bali yaitu:

\section{a. Fasilitas Lengkap}

Salah satu aspek yang seharusnya mendapat perhatian utama oleh setiap pengelola pendidikan adalah mengenai fasilitas pendidikan.

\section{b. Program Studi yang Ditawarkan Memadai}

Program studi adalah kesatuan rencana belajar sebagai pedoman penyelenggaraan pendidikan akademik dan/atau professional yang diselenggarakan atas dasar suatu kurikulum serta ditujukan agar mahasiswa dapat menguasai pengetahuan, keterampilan dan sikap sesuai dengan sasaran kurikulum. Jika di dalam suatu sekolah tinggi memiliki program studi yang memadai dan belum di miliki oleh sekolah tinggi lainnya maka ini akan menjadi nilai lebih dari sekolah tinggi tersebut.

\section{Proses Mahasiswa Memilih Kuliah di STIKES}

\section{Bina Usada Bali.}

Analytic Hierarchy Process atau yang biasa disebut AHP adalah suatumodelyang luwes yang memberikan kesempatan bagi perorangan atau kelompok untuk membangun gagasan-gagasan dan mendefinisikanpersoalandengancara membuat asumsi mereka masing-masing dan memperoleh pemecahan yang diinginkan darinya.

Dalam penelitian ini di dapat proses mahasiswa memilih kuliah di STIKES Bina Usada Bali yaitu:

\section{a. Jalur PMDK}

Penerimaan mahasiswa melalui jalur PMDK (Penelusuran Minat Dan Kemampuan) merupakan jalur penerimaan mahasiswa bagi mereka yang memiliki bakat serta minat yang biasanya tertulis di rapor dan sertifikat atau piagam.

\section{b. Jalur Umum}

Jalur Reguler yaitu jalur pendaftaran yang terbuka bagi seluruh siswa/i lulusan SMA/SMK atau sekolah lainya yang sederajat, dimana untuk dapat diterima sebagai mahasiswa baru harus mengikuti seleksi/tes Ujian Saringan Masuk (USM). Beberapa seleksi yang harus dilalui calon mahasiswa yaitu tes tulis, wawancara dan tes kesehatan.

\section{Motivasi Belajar Mahasiswa di STIKES Bina Usada Bali.}

Motivasi belajar merupakan keseluruhan daya penggerak didalam diri mahasiswa yang menimbulkan kegiatan belajar, yang menjamin kelangsungan dari kegiatan belajar dan yang memberikan arah pada kegiatan belajar, sehingga tujuan yang dikehendaki dapat tercapai.

Dalam penelitian ini di dapat hal yang memengaruhi rendahnya motivasi belajar mahasiswa yaitu :

\section{a. Adanya Faktor Umum Seperti Paksaan Orang Tua.}

Banyak mahasiswa yang merasa tidak cocok dengan jurusan yang di ambil. Mereka merasa jurusan yang mereka ambil tidak sesuai dengan minat dan bakatnya sehingga tidak berkembang dan sulit mengikuti pelajaran.

\section{b. Belajar H-1 Sebelum UAS}

Belajar merupakan proses interaksi antara individu dengan sumber belajar yang menghasilkan suatu perubahan, tingkah laku, dan pola pikir seseorang. Proses kegiatan belajar memerlukan konsentrasi yang baik dari mahasiswa. Konsentrasi belajar merupakan faktor penentu keberhasilan siswa dalam menyerap ilmu pengetahuan. Konsentrasi belajar yang baik dapat menghasilkan hasil belajar yang baik pula dan sebaliknya. Dari wawancara yang dilakukan ke empat informan menyatakan bahwa belajar H-1 sebelum UAS kurang memberi dampak yang positif hal ini dikarenakan mereka kurang konsentrasi terhadap materi yang dipelajari yang disebabkan oleh materi yang terlalu banyak dan literature yang dimiliki kurang lengkap.

\section{c. Belajar Saat UAS Dilaksanakan}

Kurangnya persiapan diri dalam menghadapi ujian akhir tentu saja akan memberi dampak nagatif terhadap hasil belajar yang akan diraih mahasiswa. 


\section{KESIMPULAN}

Berdasarkan hasil penelitian diatas, adapun simpulan dari penelitian Motivasi Belajar Mahasiswa S1 Keperawatan Semester III di STIKES Bina Usada Bali adalah:

1. Alasan-alasan mahasiswa memilih kuliah di tempat ini karena memiliki fasilitas yang lengkap serta program studi yang ditawarkan memadai.

2. Proses mahasiswa memilih Kuliah di tempat ini terdapat dua proses yaitu PMDK yang dinilai melalui 2 kriteria seperti jalur minat dan prestasi akademik dan jalur minat dan bakat. Reguler atau Umum dibagi menjadi 3 tahap yaitu tes tulis, tes wawancara dan tes kesehatan.

3. Motivasi belajar mahasiswa masih rendah hal ini disebabkan karena mahasiswa memilih jurusan bukan dari keinginan diri sendiri atau sesuai dengan bakat yang dimiliki melainkan karena adanya faktor umum yaitu orang tua, adanya kendala dalam memahami mata kuliah yang diberikan, mereka mulai termotivasi ketika mulai menyadari bahwa nilai mereka kecil dan akan mempengaruhi IPK yang digunakan sebagai acuan untuk ujian proposal maupun skripsi.

\section{DAFTAR PUSTAKA}

1. Aritonang, Keke.2008. Minat dan Motivasi dalam Meningkatkan Hasil Belajar Siswa.Jurnal Pendidikan. Penabur

2. Hamdu, Ghullam dan Agustina,Lisa. 2011. Pengaruh motivasi belajar siswa terhadap prestasi belajar IPA di Sekolah Dasar. Jurnal Penelitian Pendikan. Vol. 12 No 1. Tasikmalaya
3. Indrawan dan Yaniawati, 2014.Metodologi peneltian. Bandung: PT Refika Adiatmaedisi revisi

4. Irawan, G. (2015). Analytic Hierarchy Process.Fakultas Ilmu Pendidikan. 17 September 2018. http://journal.student.uny.ac.id

5. Kiswoyati, Amin.2011. pengaruh motivasi belajar dan kegiatan belajar siswa terhada kecakapan hidup siswa. ISSN Edisi Khusus No $1: 121$

6. Lestari, A. 2011.Hubungan Interaksi Sosial Berdasarkan Teori Schutz Dengan Prestasi Belajar Siswa.Skripsi.UPI. Bandung.

7. Moeryadi, Denny. 2009. Pemikiran fenomenologi menurut Edmund Husserl. Duplikasi oleh jurnal studi.

8. Saryono \& Anggraeni.(2011). Metodologi penelitian kualitatif dibidang kesehatan ( $\left.2^{\text {nd }} \mathrm{ed}.\right)$. Jogjakarta: Muha Medika.

9. Sugiyono. 2010. Metode Penelitian Kuantitatif, Kualitatif dan $R \& D$. Bandung: Alfabeta.

10. Susilo, R. 2011. Pendidikan kesehatan dalam keperawatan. Cetakan ke 1, Bantul: Nuha Medika.

11. Syarif, Izudin. 2012. Pengaruh Model Blended Learning Terhadap Motivasi Dan Prestasi Belajar Siswa SMK. Jurnal Pendidikan Vokasi. Vol 2, No 2.Balangan.

12. Uno, M. 2017. Model pembelajaran menciptakan proses belajar mengajar yang kreatif dan efektif. Rawamangun.PT Bumi Aksara.

13. Yusuf, Mappease. 2009. Pengaruh cara dan motivasi belajar terhadap hasil belajar programmable logic controller (PLC) siswa kelas III jurusan listik SMK negeri 5 Makasar. Jurnal MEDTEK. Vol. 1, No 2. Semarang 